\title{
Association between a deletion/insertion polymorphism in the $\alpha 2 B$-adrenergic receptor gene and insulin secretion and Type 2 diabetes. The Finnish Diabetes Prevention Study
}

\author{
N. Siitonen ${ }^{1}$ J. Lindström ${ }^{2}$ J. Eriksson ${ }^{2}$ T. T. Valle ${ }^{2}$ H. Hämäläinen ${ }^{3}$ P. Ilanne-Parikka ${ }^{4}$ \\ S. Keinänen-Kiukaanniemi ${ }^{5,6}$ • J. Tuomilehto ${ }^{2,7} \cdot$ M. Laakso ${ }^{8} \cdot$ M. Uusitupa ${ }^{1,9}$ \\ ${ }^{1}$ Department of Clinical Nutrition and Food and Health Research Center, University of Kuopio, Kuopio, Finland \\ 2 Department of Epidemiology and Health Promotion, Diabetes and Genetic Epidemiology Unit, National Public Health Institute, \\ Helsinki, Finland \\ ${ }^{3}$ Research Department, Social Insurance Institution, Turku, Finland \\ ${ }^{4}$ Finnish Diabetes Association and Department of Internal Medicine, Tampere University Hospital, Tampere, Finland \\ ${ }^{5}$ Department of Public Health Science and General Practice, Oulu University Hospital, University of Oulu, Oulu, Finland \\ ${ }^{6}$ Department of Sport Medicine, Oulu Deaconess Institute, Oulu, Finland \\ ${ }^{7}$ Department of Public Health, University of Helsinki, Helsinki, Finland \\ ${ }^{8}$ Department of Medicine, University of Kuopio, Kuopio, Finland \\ ${ }^{9}$ Department of Medicine, Kuopio University Hospital, Kuopio, Finland
}

\section{Abstract}

Aims/hypothesis. Impaired insulin secretion has a strong genetic component. In this study we investigated whether the 12 Glu9 polymorphism in the gene encoding the $\alpha 2 \mathrm{~B}$-adrenergic receptor $(A D R A 2 B)$ is associated with insulin secretion and/or the incidence of Type 2 diabetes in individuals with impaired glucose tolerance. Methods. We investigated a total of 506 subjects with impaired glucose tolerance participating in the Finnish Diabetes Prevention Study (DPS). Participants were randomly assigned to an intervention group or a control group. Anthropometric measurements and an oral glucose tolerance test were performed at baseline and at annual follow-up. In a subgroup of patients $(n=83)$, a frequently sampled intravenous glucose tolerance test (FSIGT) was performed at baseline.

Results. All patients had similar anthropometric measurements and insulin and glucose levels at baseline. Multiple logistic regression analysis revealed significant interaction $(p=0.003)$ between study group and genotype across the entire study population. In the control group, subjects with the Glu9 allele had an increased risk of developing Type 2 diabetes compared with subjects with the Glu12/12 genotype (odds ratio $[\mathrm{OR}]=2.68,95 \%$ CI 1.02-7.09, $p=0.047$ for Glu12/12, and $\mathrm{OR}=5.17,95 \%$ CI 1.76-15.21, $p=0.003$ for Glu9/9). This increased risk was not observed in the intervention group, who showed significant weight loss during the trial. In the subgroup who underwent the FSIGT, subjects with the Glu9/9 genotype showed the lowest acute insulin response ( $p=0.005$ for trend). Conclusions/interpretation. The 12 Glu9 polymorphism of $A D R A 2 B$ is associated with impaired firstphase insulin secretion and may predict the development of Type 2 diabetes in subjects with impaired glucose tolerance who are not subjected to a lifestyle intervention.

Keywords $\alpha 2 \mathrm{~B}$-adrenergic receptor - Gene - Impaired glucose tolerance $\cdot$ Insulin secretion - Intervention . Polymorphism - Type 2 diabetes · Waist - Weight loss
Received: 9 February 2004 / Accepted: 1 June 2004

Published online: 28 July 2004

C) Springer-Verlag 2004

N. Siitonen ( $)$

Department of Clinical Nutrition and Food

and Health Research Center, University of Kuopio,

P.O. Box 1627, 70211 Kuopio, Finland

E-mail: nsiitone@hytti.uku.fi

Tel.: +35-817162769, Fax: +35-817162792

Abbreviations: AIR, acute insulin response $\cdot$ AR, adrenergic receptor $\cdot \mathrm{BMR}$, basal metabolic rate $\cdot \mathrm{DI}$, disposition index ·

\section{Introduction}

Environmental factors, such as diet and sedentary lifestyle, contribute to the pathogenesis of Type 2 diabetes. However, the disease also has a strong genetic

DPS, the Finnish Diabetes Prevention Study · FSIGT, frequently sampled intravenous glucose tolerance test $\mathrm{OR}$, odds ratio $\cdot \mathrm{S}_{\mathrm{G}}$, glucose effectiveness $\cdot \mathrm{S}_{\mathrm{I}}$, insulin sensitivity index 
component $[1,2]$. The genetic basis of Type 2 diabetes is polygenic, heterogeneous and still largely unknown [1]. Pathophysiologically, individuals with Type 2 diabetes exhibit two major metabolic defects: insulin resistance and failure of the pancreatic beta cells to increase their insulin secretion to compensate for the insulin resistance [1]. Both of these defects occur early in the development of Type 2 diabetes, but due to the heterogeneous nature of the disease their importance varies between individuals [2]. Although insulin resistance has long been considered to be a characteristic feature of Type 2 diabetes [3], impaired beta cell function is now also recognised as an early and critical component of the disease, resulting in impaired glucose metabolism [4]. Some studies even suggest that impaired beta cell function could precede insulin resistance when confounding factors such as age, sex and obesity are taken into consideration [2]. A high heritability has been demonstrated for beta cell function and insulin secretion [5], but the underlying genetic defects have not yet been elucidated in detail, except for monogenic cases of MODY $[1,2]$.

The catecholamines adrenaline and noradrenaline mediate many physiological effects in various tissues by binding to distinct adrenergic receptors (AR). Three human $\alpha 2$-adrenergic receptor ( $\alpha 2$-AR) subtypes have been identified ( $\alpha 2 \mathrm{~A}-, \alpha 2 \mathrm{~B}-$ and $\alpha 2 \mathrm{C}-\mathrm{AR})$ that are encoded by three distinct genes located on chromosomes 10, 2 and 4 respectively $[6,7,8]$. The $\alpha 2$-ARs mediate a wide variety of functions, including regulation of blood pressure, sympathetic tone, lipolysis and insulin secretion $[9,10]$. The specific functions of each subtype are not fully understood at present. However, it seems likely that many of the biological functions of the $\alpha 2$-ARs are mediated by more than one $\alpha 2-\mathrm{AR}$ subtype [10]. The $\alpha 2-\mathrm{AR}$ subtypes are widely distributed in human tissues and display subtype-specific expression in some of them [11]. All three $\alpha 2$-AR subtypes are expressed in human pancreas in both exocrine and endocrine cells, including the beta cells [12].

Human $\alpha 2 \mathrm{~B}-\mathrm{AR}$ is encoded by $A D R A 2 B$ located on chromosome 2 [6]. A polymorphism (12Glu9) leading to the deletion/insertion of three glutamic acid residues from an acidic stretch of 16 amino acids in the third intracellular loop has been described [13]. This polymorphism has a pronounced effect on receptor phosphorylation and results in the loss of agonistpromoted desensitisation [14]. It has been found to be associated with: (i) a reduced basal metabolic rate in obese subjects [13]; (ii) increased body weight among non-diabetic subjects [15]; (iii) an increased risk of acute coronary events [16]; (iv) impaired flow-mediated dilation of the brachial artery $[16,17]$; and (v) increased sympathetic nervous system activity [18]. In addition, the 12 Glu 9 polymorphism has shown an interactive effect with a $\beta 3-A R$ gene polymorphism on fat mass [19], although an association with basal metabolic rate could not be replicated in this study.

The purpose of this study was to examine whether the $12 G l u 9$ polymorphism of $A D R A 2 B$ is associated with insulin secretion and/or the risk of Type 2 diabetes using data from the Finnish Diabetes Prevention Study (DPS).

\section{Subjects and methods}

The Finnish Diabetes Prevention Study. The DPS is a longitudinal intervention study being carried out in five research clinics. The objective of the DPS was to assess the effect of lifestyle intervention on diabetes risk in overweight, middleaged subjects with impaired glucose tolerance. The inclusion and exclusion criteria, design, intervention programme and main results of the DPS have been described earlier in detail $[20,21]$. In brief, a total of 522 overweight subjects (BMI $31.1 \pm 4.6 \mathrm{~kg} / \mathrm{m}^{2}$ ) with impaired glucose tolerance were randomly allocated into one of two groups: a lifestyle and diet intervention group or a control group. Randomisation was stratified according to the clinic attended, sex and mean plasma glucose concentration $2 \mathrm{~h}$ after oral glucose load (7.8-9.4 or $9.5-11.0 \mathrm{mmol} / \mathrm{l})$. Subjects in the intervention group were given individually tailored dietary advice and were instructed to increase their physical activity. Dietary guidance was aimed towards reducing body weight by 5 to $10 \%$, reducing both total and saturated fat intake and increasing dietary fibre intake. The control group received general information on the benefits of a healthy diet, physical activity and weight reduction. All participants gave written informed consent, and the study protocol was approved by the ethics committee of the National Public Health Institute in Helsinki, Finland.

Medical examinations and anthropometric measurements. A medical history was taken and a physical examination was performed at baseline and at each annual follow-up visit. BMI was calculated as: weight $(\mathrm{kg}) /(\text { height }[\mathrm{m}])^{2}$. Waist circumference was measured midway between the lowest rib and iliac crest. Measurements recorded at baseline and 3-year examination were used in the present study. The cumulative incidence of Type 2 diabetes was calculated after a mean follow-up period of 3.2 years [20].

Assessment of glucose and insulin metabolism. A 2-h oral glucose tolerance test was performed at baseline and annually. Plasma glucose and insulin levels were measured before ( 0 min) and $120 \mathrm{~min}$ after a glucose dose of $75 \mathrm{~g}$. Plasma glucose was measured locally by standard methods and the measurements were standardised by the central laboratory in Helsinki as previously described [20]. Serum insulin was measured by RIA (Phadaseph Insulin RIA 100, Pharmacia Diagnostica, Uppsala, Sweden). The intra-assay coefficient of variation was $5.3 \%$ and the interassay coefficient of variation was $7.6 \%$. The diagnosis of diabetes and other categories of glucose intolerance were based on the criteria adopted by the World Health Organization in 1985 [22]. Accordingly, impaired glucose tolerance was defined as a 2-h plasma glucose concentration within the range of 7.8 to $11.0 \mathrm{mmol} / \mathrm{l}$ and a fasting plasma glucose concentration of less than $7.8 \mathrm{mmol} / \mathrm{l}$. The diagnosis of impaired glucose tolerance was based on the mean value of two oral glucose tolerance tests. The diagnosis of diabetes (fasting plasma glucose $\geq 7.8 \mathrm{mmol} / \mathrm{l}$ or 2 -h plasma glucose $\geq 11.0 \mathrm{mmol} / \mathrm{l}$ ) was confirmed by a second oral glucose 
tolerance test. The homeostasis model assessment for insulin resistance was calculated using the following formula: fasting plasma glucose $(\mathrm{mol} / \mathrm{l}) \times$ fasting serum insulin $(\mu \mathrm{U} / \mathrm{l}) / 22.5$.

In the Kuopio clinic, the frequently sampled insulin-modified intravenous glucose tolerance test (FSIGT) was performed at baseline as previously described [23]. In total, 87 subjects participated in the FSIGT [24], and those with an available DNA sample ( $n=83)$ were included in this study. First, two i.v. catheters were inserted into the antecubital veins on both arms and the fasting samples were drawn. An i.v. dose of $300 \mathrm{mg} / \mathrm{kg}$ of glucose was given as a $50 \%$ solution over $1.5 \mathrm{~min}$, followed by $10 \mathrm{ml}$ of a $0.9 \% \mathrm{NaCl}$ solution. A $0.9 \% \mathrm{NaCl}$ solution was then slowly infused until, $20 \mathrm{~min}$ after the glucose load, a 0.03$\mathrm{U} / \mathrm{kg}$ bolus of insulin was rapidly injected, after which $\mathrm{NaCl}$ infusion was continued for another $1.5 \mathrm{~min}$. Venous blood samples were collected before the glucose load $(-5 \mathrm{~min}$ and $0 \mathrm{~min}$ ) and 23 times after the glucose load (at 2, 4, 6, 8, 10, 12, $14,16,19,22,24,27,30,40,50,60,70,90,100,120,140$, 160 and $180 \mathrm{~min})$. Plasma glucose concentration was analysed by a glucose oxidase method (Glucose Auto \& Stat, Model GA-110, Daiichi, Kyoto, Japan). The intra-assay coefficient of variation was 1.2 to $2 \%$ over the concentration range of 5.5 to $22.9 \mathrm{mmol} / \mathrm{l}$, and the interassay coefficient of variation was 1.7 to $1.8 \%$ over the concentration range of 5.1 to $15.3 \mathrm{mmol} / \mathrm{l}$. Plasma insulin was analysed by RIA (Phadaseph Insulin RIA 100), for which the intra-assay coefficient of variation was $7.7 \%$ and the interassay coefficient of variation over the 15 to 114-mU/1 range was 9.2 to $10.0 \%$. Glucose effectiveness $\left(\mathrm{S}_{\mathrm{G}}\right)$ and insulin sensitivity index $\left(\mathrm{S}_{\mathrm{I}}\right)$ were calculated with the MINMOD program [25]. The acute insulin response (AIR) was determined by calculating the area under the curve above the baseline level from 0 to $10 \mathrm{~min}$ after the glucose load. The disposition index (DI) was calculated as the product of AIR and $\mathrm{S}_{\mathrm{I}}[26]$.

Genotyping. DNA was available for 506 subjects. The 12 Glu9 polymorphism of the $A D R A 2 B$ gene was analysed by PCR and gel electrophoresis as previously described [15]. The following primers were used for PCR amplification: forward $5^{\prime}$-AGGGTGTTTGTGGGGCATCTCC-3', and reverse 5'-CAAGCTGAGGCCGGAGACACTG-3' (OliGold, Eurogentec, Seraing, Belgium). PCR products were separated according to size (long allele $112 \mathrm{bp}$ and short allele $103 \mathrm{bp}$ ) by gel electrophoresis using a 3\% agarose gel (NuSieve GTG, BioWhittaker Molecular Applications, Rockland, Me., USA).

Statistical methods. The significance of differences in genotype frequencies were analysed using the two-tailed Fisher's exact test in StatXact-4 program version 4.0.1 (Cytel Software Corporation, Cambridge, Mass., USA). The Hardy-Weinberg equilibrium was tested by the chi square test. Otherwise the data were analysed using SPSS for Windows, Release 11.0.1. (SPSS, Chicago, Ill., USA). Data are presented as means \pm SD or as medians + interquartile range. A $p$ value of less than 0.05 was considered significant. Normal distribution was tested with the Kolmogorov-Smirnov (Lilliefors) test, and logarithmic transformation was used to achieve normal distribution when needed. The differences in continuous variables between genotypes were evaluated with the univariate ANOVA, general linear model. Adjustments for age, sex and BMI were used when appropriate. For variables whose distribution was not normal even after logarithmic transformation, the KruskalWallis test was used to evaluate statistical differences between genotypes. To explore the relationship between insulin secretion and insulin sensitivity for each genotype, an exponential curve was fitted and the coefficients of determination were calculated. The significance of differences in the incidence of dia- betes between genotypes was analysed by the chi square test. Logistic regression analysis was used to assess whether the Glu9 allele predicted the development of Type 2 diabetes. In logistic regression models, the genotypes were coded as $0=$ Glu12/12, $1=$ Glu12/9 and $2=$ Glu9/9; sex was encoded as $0=$ men, 1 = women; and study groups were coded as $0=$ control group, 1 = intervention group. In logistic regression and diabetes incidence analyses, the number of subjects used was either 478 (due to 28 drop-outs during study period) or 476 (due to additional missing baseline waist circumference data for two subjects).

\section{Results}

Genotype frequency. In the DPS study population as a whole, frequencies of the genotypes of the $12 \mathrm{Glu} 9$ polymorphism in ADRA2B were: Glu12/12 28.7\%, Glu12/9 50.8\% and Glu9/9 20.6\%. The genotype frequencies were in Hardy-Weinberg equilibrium and did not differ significantly between the intervention and the control group.

Anthropometric and biochemical data. At baseline, there were no significant differences between genotypes with respect to age, sex, anthropometric measurements, plasma glucose or serum insulin levels (Table 1). Changes in weight or waist circumference from baseline to Year 3 examination did not differ between genotypes in either study group (data not shown). Due to the successful intervention programme, the changes in weight and waist circumference were significantly greater in the intervention group than in the control group $(p<0.001$ for both, data not shown).

The incidence of Type 2 diabetes according to ADRA2B genotype. During the mean follow-up period of 3.2 years, 72 subjects with available genotype data developed Type 2 diabetes (21 in the intervention group and 51 in the control group).

The relationship between the 12 Glu9 polymorphism and the incidence of diabetes was analysed using logistic regression (Table 2). This revealed significant interaction between $A D R A 2 B$ genotype and study group ( $p=0.003)$ and nearly significant interaction between the genotype and waist circumference measured at baseline $(p=0.052)$.

Logistic regression analysis was applied separately to the control and intervention groups (Table 3). In the control group, the $A D R A 2 B$ genotype was a significant predictor of Type 2 diabetes. Compared with subjects with the Glu12/12 genotype, subjects with the Glu9/9 genotype had a 5.2-fold increased risk of Type 2 diabetes (odds ratio $[\mathrm{OR}]=5.17,95 \%$ CI $1.76-15.21$, $p=0.003$ ) and subjects with the Glu12/9 genotype had a 2.7-fold increased risk $(\mathrm{OR}=2.68,95 \%$ CI $1.02-7.09, p=0.047$ ), even when age, sex, weight change, waist circumference and fasting plasma glu- 
Table 2. Logistic regression analysis for the development of Type 2 diabetes in the study population from the Finnish Diabetes Prevention Study

\begin{tabular}{|c|c|c|c|}
\hline & $p$ value & $\begin{array}{l}\text { Odds } \\
\text { ratio }\end{array}$ & $95 \% \mathrm{CI}$ \\
\hline $\begin{array}{l}\text { Genotype a x Study } \\
\text { group }\end{array}$ & 0.003 & & \\
\hline $\begin{array}{l}\text { Genotype }{ }^{a} \text { x Waist } \\
\text { circumference }^{b}\end{array}$ & 0.052 & & \\
\hline Weight changec & $<0.001$ & 0.86 & $0.81-0.92$ \\
\hline Fasting plasma glucose $\mathrm{e}^{\mathrm{d}}$ & $<0.001$ & 3.36 & $2.21-5.11$ \\
\hline
\end{tabular}

Age, sex, waist circumference, study group and genotype were controlled in this model. Sex was encoded as $0=$ men and $1=$ women. Study groups were encoded as $0=$ intervention group and $1=$ control group.

a Genotype Glu12/12 was regarded as a reference

${ }^{\mathrm{b}}$ measured at baseline examination

c calculated as weight $(\mathrm{kg})_{\text {baseline }}$-weight $(\mathrm{kg})_{\text {Year 3/last measurement }}$

d fasting plasma glucose ( $\mathrm{mmol} / \mathrm{l})$ was measured at baseline examination

Table 3. Logistic regression analysis for the development of Type 2 diabetes in the control group and in the intervention group of the study

\begin{tabular}{|c|c|c|c|}
\hline & $p$ value & $\begin{array}{l}\text { Odds } \\
\text { ratio }\end{array}$ & $95 \%$ CI \\
\hline \multicolumn{4}{|l|}{ Control group ( $n=237$ ) } \\
\hline $\begin{array}{l}\text { Genotype Glu12/9a } \\
\text { Genotype Glu9/9a } \\
\text { Weight change } \\
\text { Waist circumference }^{\mathrm{c}} \\
\text { Fasting plasma glucose }^{\mathrm{d}}\end{array}$ & $\begin{array}{r}0.047 \\
0.003 \\
0.001 \\
0.531 \\
<0.001\end{array}$ & $\begin{array}{l}2.68 \\
5.17 \\
0.88 \\
1.01 \\
3.40\end{array}$ & $\begin{array}{l}1.02-7.09 \\
1.76-15.21 \\
0.81-0.95 \\
0.98-1.05 \\
2.02-5.73\end{array}$ \\
\hline \multicolumn{4}{|l|}{ Intervention group $(n=239)$} \\
\hline $\begin{array}{l}\text { Genotype Glu12/9a } \\
\text { Genotype Glu9/9a } \\
\text { Weight changeb } \\
\text { Waist circumference } \\
\text { Fasting plasma glucose }\end{array}$ & $\begin{array}{l}0.205 \\
0.049 \\
0.001 \\
0.002 \\
0.001\end{array}$ & $\begin{array}{l}0.49 \\
0.09 \\
0.79 \\
1.09 \\
3.21\end{array}$ & $\begin{array}{l}0.16-1.48 \\
0.01-0.99 \\
0.69-0.91 \\
1.03-1.15 \\
1.60-6.45\end{array}$ \\
\hline
\end{tabular}

Age and sex were controlled in these models. Sex was encoded as $0=$ men and $1=$ women .

a Genotype Glu12/12 was regarded as a reference

b calculated as weight $(\mathrm{kg})_{\text {baseline }}$-weight $(\mathrm{kg})_{\text {Year 3/last measurement }}$

${ }^{\mathrm{c}}$ measured at baseline examination

$\mathrm{d}$ fasting plasma glucose $(\mathrm{mmol} / \mathrm{l})$ was measured at baseline examination

cose were included in the model (Table 3 ). In the intervention group, the Glu9/9 genotype was associated with a lower risk of Type 2 diabetes $(\mathrm{OR}=0.09,95 \%$ CI $0.01-0.99, p=0.049$ ) than in the control group, and only one subject with this genotype developed Type 2 diabetes in this group.

Table 4 shows the crude numbers and percentages of subjects who developed Type 2 diabetes according to genotype in the DPS group as a whole and in the two study groups. In line with the above data, the inci- 
Table 4. Numbers and percentages of subjects who developed Type 2 diabetes during a mean follow-up period of 3.2 years according to $A D R A 2 B$ genotype in the entire study population and the two study groups

\begin{tabular}{|c|c|c|c|c|}
\hline & Glu12/12 & Glu12/9 & Glu9/9 & $p$ value $^{\mathrm{a}}$ \\
\hline Entire study population $(n=478)$ & $17(12.5)$ & $36(14.8)$ & $19(19.4)$ & 0.341 \\
\hline Intervention group $(n=240)$ & $9(13.8)$ & $11(8.3)$ & $1(2.3)$ & 0.113 \\
\hline
\end{tabular}

Values are $n(\%)$. ${ }^{\text {a }} \chi^{2}$ test ( $p$ value for trend)

Table 5. Logistic regression analysis for the development of Type 2 diabetes in the study population divided into two groups according to waist circumference

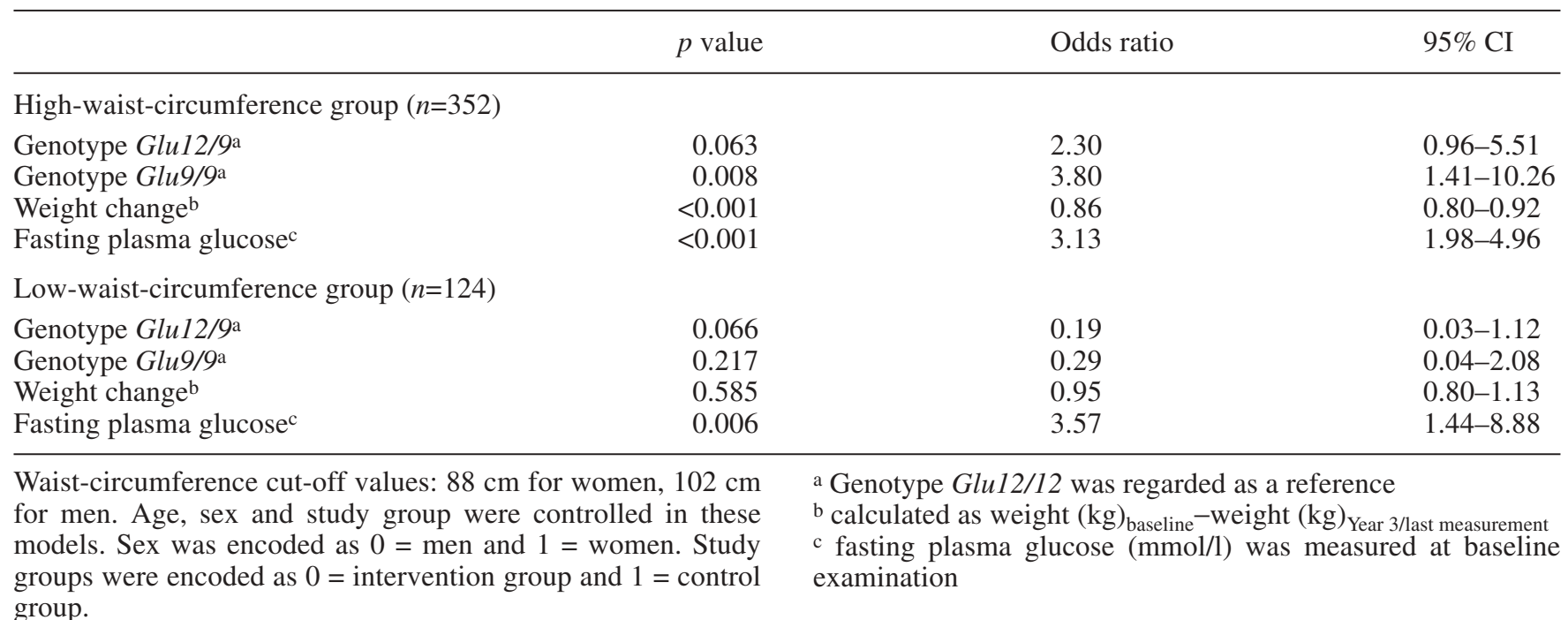

Table 6. Baseline insulin secretion and insulin sensitivity data according to $A D R A 2 B$ genotype in a subgroup of subjects for whom the frequently sampled intravenous glucose tolerance test was performed

\begin{tabular}{lccc}
\hline & Glu12/12 $(n=32)$ & Glu12/9 $(n=33)$ & Glu9/9 $(n=18)$ \\
\hline $\mathrm{AIR}_{0-10}\left(\mathrm{mU}^{-1} \cdot \mathrm{min}^{-1}\right)$ & $252.0(158.7-535.6)$ & $151.1(67.6-253.2)$ & $95.2(55.4-201.5)$ \\
$\mathrm{S}_{\mathrm{I}}\left(\times 10^{-4} \cdot \mathrm{min}^{-1} \cdot \mu \mathrm{U}^{-1} \cdot \mathrm{ml}^{-1}\right)$ & $1.8(1.0-2.7)$ & $1.4(0.9-2.8)$ & $1.7^{\mathrm{b}}(1.1-2.4)$ \\
$\mathrm{S}_{\mathrm{G}}\left(\mathrm{min}^{-1} \cdot 10^{2}\right)$ & $1.7(1.4-2.0)$ & $1.5(1.2-1.9)$ & $0.004^{\mathrm{a}}$ \\
$\mathrm{DI}\left(\mathrm{S}_{\mathrm{I}} \mathrm{x}\right.$ AIR) & $491.7(226.3-831.1)$ & $241.4(114.7-406.5)$ & $0.636^{\mathrm{c}}$ \\
\hline
\end{tabular}

Values are medians (interquartile ranges).

${ }^{a} p$ values for $\mathrm{AIR}_{0-10}, \mathrm{~S}_{\mathrm{I}}$ and DI were adjusted for age, sex and BMI

b $n=17$

dence of Type 2 diabetes was highest in the control group in subjects with the Glu9/9 genotype and lowest in subjects with the Glu12/12 genotype, while subjects with the Glu12/9 genotype exhibited an intermediate incidence of diabetes ( $p=0.014$ for trend). Neither the DPS study group as a whole nor the lifestyle intervention group showed any significant differences in the incidence of diabetes with respect to genotype.

Because logistic regression revealed an interaction between genotype and waist circumference, we divided all study subjects into two groups according to their waist circumference, applying a cut-off value of $88 \mathrm{~cm}$ for women and $102 \mathrm{~cm}$ for men [27]. In the
${ }^{c} p$ value tested by Kruskal-Wallis test. $\mathrm{AIR}_{0-10}$, acute insulin response to glucose $0-10 \mathrm{~min} ; \mathrm{S}_{\mathrm{I}}$, insulin sensitivity index; $\mathrm{S}_{\mathrm{G}}$, glucose effectiveness; DI, disposition index

high-waist-circumference group $(n=352)$, the incidence of diabetes increased gradually with the number of Glu9 alleles ( $p=0.011$ for trend) (Fig. 1). Conversely, in the low-waist-circumference group $(n=124)$, where the incidence of diabetes was low, Glu9 allele carriers had an even lower incidence of diabetes than subjects with the Glu12/12 genotype ( $p=0.002$ for trend).

Logistic regression analysis was applied separately to low- and high-waist-circumference groups (Table 5). In the high-waist-circumference group, subjects with the Glu9/9 genotype had a 3.8-fold increased risk of diabetes $(\mathrm{OR}=3.80,95 \%$ CI 


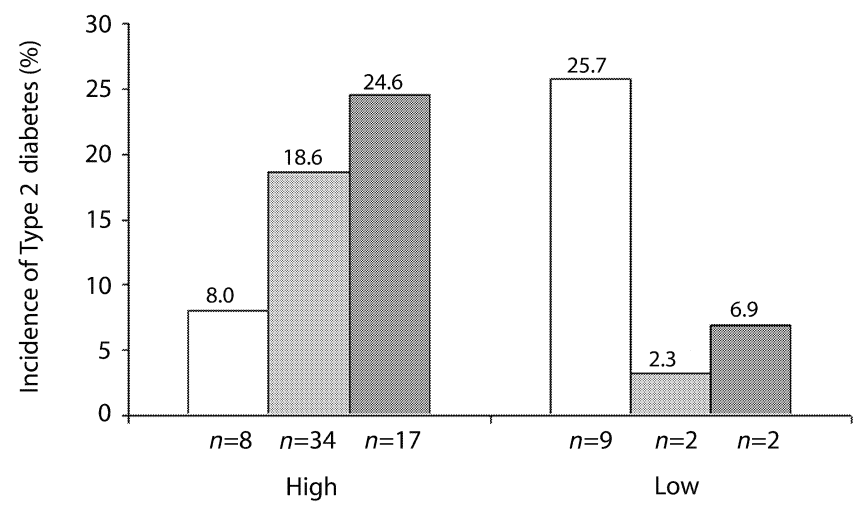

Fig. 1. Incidence of Type 2 diabetes according to $A D R A 2 B$ genotype (white bars, Glu12/12; light grey bars, Glu12/9; dark grey bars, Glu9/9) after an average follow-up period of 3.2 years in the whole study population divided into high- and low-waist-circumference groups. High-waist-circumference group (High): $n=352, p=0.011$ for comparison of all three genotypes; low-waist-circumference group (Low): $n=124$, $p=0.002$ for comparison of all three genotypes

$1.41-10.26, p=0.008)$ compared with subjects with the Glu12/12 genotype. A similar trend was seen in subjects with the Glu12/9 genotype (OR=2.30, 95\% CI 0.96-5.51, $p=0.063)$. In the low-waist-circumference group, genotype was not significantly related to diabetes risk, although the risk of diabetes in subjects with the Glu12/9 genotype seemed to be lower than that in subjects with the Glu12/12 genotype (OR=0.19, 95\% CI 0.03-1.12, $p=0.066$ ) (Table 5).

Insulin secretion and insulin sensitivity. The baseline characteristics of the subgroup that underwent the FSIGT at the Kuopio clinic are shown in Table 1. The results of the FSIGT performed at baseline are shown in Table 6. Genotype frequencies in this subpopulation (Glu12/12 36.8\%, Glu12/9 37.9\% and Glu9/9 20.7\%) were in Hardy-Weinberg equilibrium and did not differ significantly from the genotype frequencies of the study population as a whole.

There were significant differences $(p=0.004)$ between genotypes with respect to AIR; subjects with the Glu12/12 genotype exhibited the highest and those with Glu9/9 genotype the lowest AIR values. Genotype differences were also significant $(p=0.003)$ when beta cell function was assessed using the DI. Figure 2 shows the relationship between AIR and $S_{I}$ for each genotype group. An exponential relationship was seen between AIR and $\mathrm{S}_{\mathrm{I}}\left(r^{2}=0.223, p=0.006\right)$ in subjects with Glu12/12 genotype. In Glu9 allele carriers, the exponential relationship was either not significant $\left(r^{2}=0.106, p=0.065\right.$ for Glu12/9) or absent $\left(r^{2}=0.010\right.$, $p=0.704$ for Glu9/9).

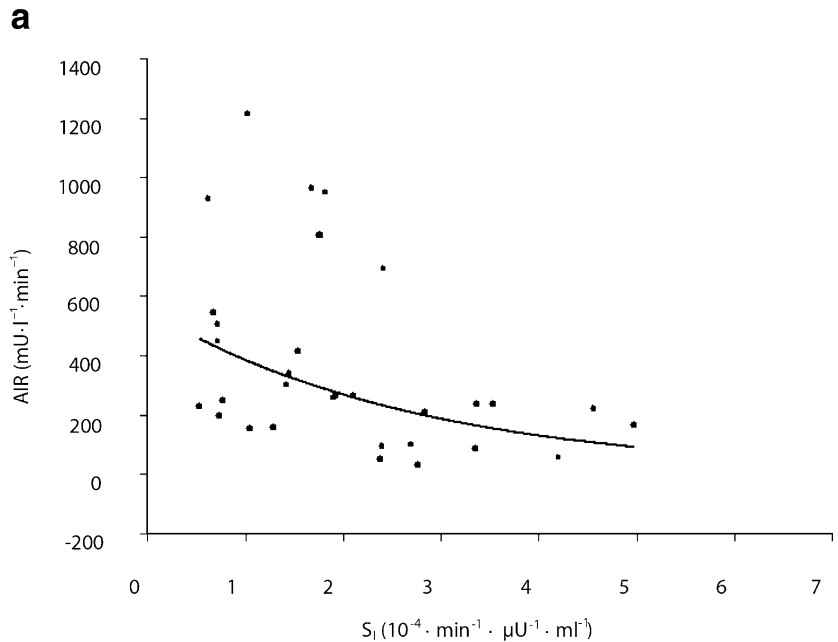

b

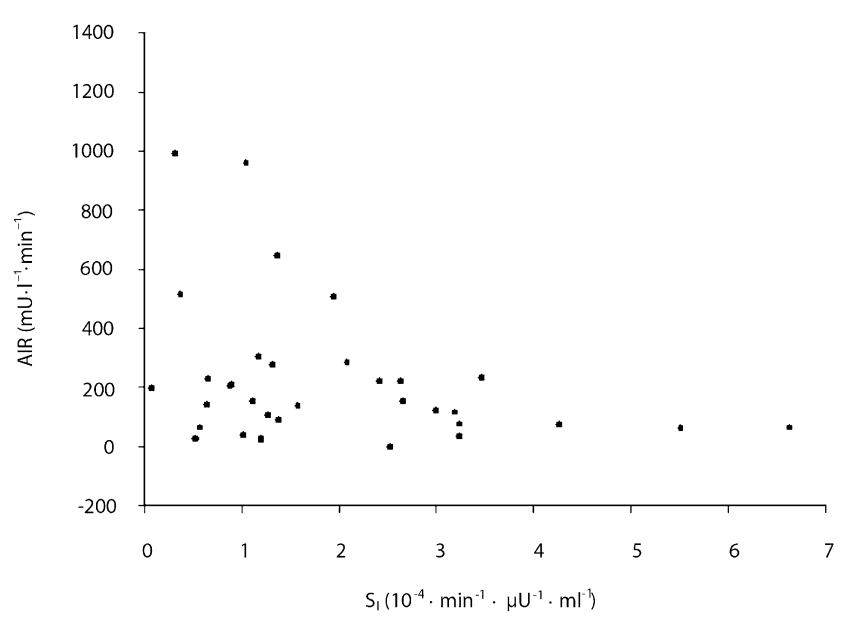

C

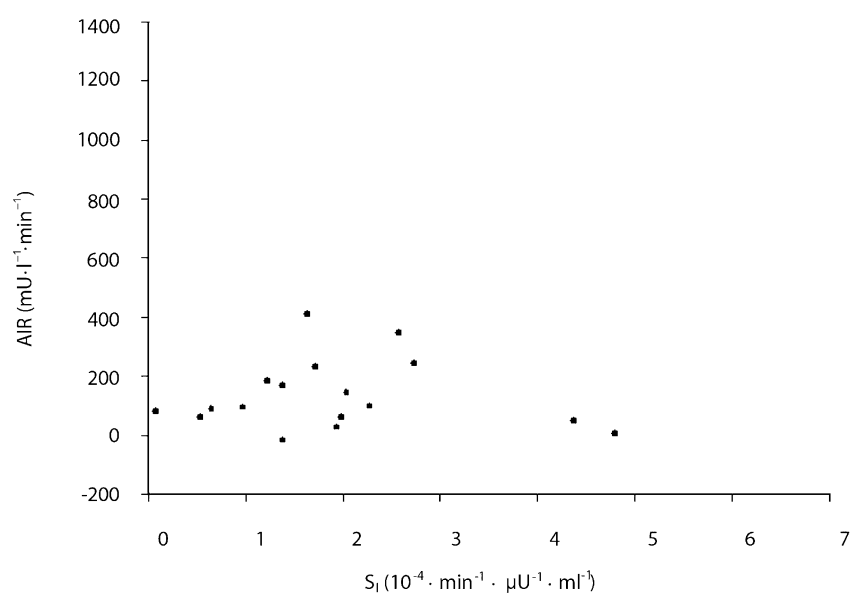

Fig. 2. Graphs showing the exponential relationship between acute insulin response (AIR) and insulin sensitivity index $\left(\mathrm{S}_{\mathrm{I}}\right)$ according to $A D R A 2 B$ genotype in a subgroup of the study population. Results show (a) Glu12/12 ( $n=32, r^{2}=0.223$, $p=0.006)$, (b) Glu12/9 $\left(n=33, r^{2}=0.106, p=0.065\right)$ and (c) Glu9/9 $\left(n=17, r^{2}=0.010, p=0.704\right)$ 


\section{Discussion}

In the present study, we have shown that the 12 Glu9 polymorphism in $A D R A 2 B$ is associated with impaired beta cell function assessed as an acute AIR or DI in a group of Finnish subjects with impaired glucose tolerance. Interestingly, this genetic polymorphism may also predispose its carriers to Type 2 diabetes.

Both insulin resistance and beta cell dysfunction are important factors in the pathogenesis of Type 2 diabetes, and a feedback loop exists between insulin secretion by the beta cells and the insulin sensitivity of its target tissues [4]. The ability of beta cells to compensate for reduced insulin sensitivity is described by a hyperbolic relationship between insulin response and insulin sensitivity, which was first described by Bergman and co-workers in 1981 [28]. They suggested that the product of insulin sensitivity and insulin secretion is equal to a constant named the DI. Changes in insulin sensitivity are followed by alterations in insulin secretion by beta cells such that the DI remains constant in healthy individuals $[4,26]$. In our study, both the AIR and the DI differed significantly between genotypes, being lowest in subjects with the Glu9/9 genotype, intermediate in subjects with the Glu12/9 genotype and highest in subjects with the Glu12/12 genotype. The genotype groups also showed differences in the exponential relationship between insulin response and insulin sensitivity. It should be noted that all of the subjects included in this study were glucose intolerant, and it might be presumed that the secretion capacity of the beta cells was already disturbed to some extent in all subjects. Nevertheless, a significant difference in beta cell function was seen between genotype groups, and the difference in secretory capacity was significant even when not adjusted for insulin sensitivity.

As insulin sensitivity decreases, the requirement for insulin secretion by the beta cells increases; thus, individuals with an impaired capacity to secrete insulin are predisposed to Type 2 diabetes [29]. The heritability of beta cell function, when assessed as DI, has been reported as $67 \%$ in a group of subjects who had either impaired or normal glucose tolerance, and $70 \%$ in subjects who had normal glucose tolerance [5]. In previous studies, a few genetic polymorphisms have been associated with impaired insulin secretion in humans, e.g. the $A r g 64$ variant of $\beta 3-A R$ [30], the $-866 G / A$ polymorphism in the promoter region of UCP2 [31] and the Gly972>Arg variant of IRS-1 [32]. In the present study, the $A D R A 2 B$ deletion/insertion polymorphism has, to our knowledge, been associated with impaired insulin secretion for the first time. The $A D R A 2 B$ genotype frequencies in our study population did not differ significantly from those previously reported for diabetic and non-diabetic Finnish subjects [15].

Blockage of $\alpha 2$-ARs has been shown to improve glucose-potentiated insulin secretion in Type 2 diabe- tes [33], and results from studies on transgenic mice provide evidence that in vivo over-expression of $\alpha 2$ ARs in beta cells can lead to impaired insulin secretion and glucose intolerance [34]. A highly acidic stretch of 16 amino acids in the third intracellular loop of $\alpha 2 B-A R$ plays a critical role in short-term, agonistpromoted desensitisation, which results in uncoupling of the receptor-G-protein complex [35]. The common deletion/insertion polymorphism involving three glutamic acid residues in the third intracellular loop of the $\alpha 2 B-A R$ has been shown to influence receptor function by impairing agonist-promoted receptor phosphorylation and desensitisation [14]. Based on this observation, we postulate that impairment of $\alpha 2 \mathrm{~B}-\mathrm{AR}$ desensitisation due to the 12 Glu9 deletion/insertion polymorphism causes prolonged inhibition of insulin secretion from pancreatic beta cells. Through this mechanism the polymorphism may constitute one of the genetic components underlying insulin secretion, and could explain the genetic predisposition of certain individuals to Type 2 diabetes. Furthermore, a clear gene dosage effect was seen in our study: subjects possessing two alleles encoding the functional receptor produced a full insulin response, whereas subjects with the Glu12/9 genotype exhibited an intermediate glucose-stimulated insulin secretion.

Interestingly, in our study, significant interaction was seen between $A D R A 2 B$ genotype and study group: the Glu9 allele was a significant predictor of Type 2 diabetes in the control group, but not in the group receiving intensive diet and exercise counselling. The major difference between the two study groups was that a significantly larger average weight loss was achieved by subjects in the intervention group compared with those in the control group. In the DPS study, long-term weight loss resulted in an improvement in insulin sensitivity [24], which may decrease the need for the beta cells to secrete large amounts of insulin [4, 26]. Hence, we suggest that lifestyle intervention leading to weight loss may greatly benefit carriers of the Glu9 allele in the prevention of Type 2 diabetes. More importantly, significant interaction was also seen between $A D R A 2 B$ genotype and waist circumference with respect to the incidence of diabetes. In the presence of abdominal obesity, the risk of Type 2 diabetes was increased by a factor of 3.8 in the Glu9/9 group and by a factor of 2.3 in the Glu12/9 group, compared with the Glu12/12 group. When subjects were stratified according to waist circumference, the Glu12/9 genotype was associated with a lower risk of Type 2 diabetes than the Glu12/12 genotype within the low-waist-circumference group. However, these results should be interpreted with caution due to the smaller group size and lower incidence of diabetes in the low-waist-circumference group. Considering that central obesity is a major risk factor for insulin resistance [2, 4], and waist circumference is the best overall predictor of abdominal visceral fat 
mass [36], our results suggest that the compensatory mechanism of insulin secretion employed by beta cells, although impaired due to the Glu9 allele, may be sufficient to protect individuals against the development of Type 2 diabetes in the absence of central adiposity. It should be noted that, in addition to significantly larger weight loss, subjects in the intervention group also achieved a significantly larger reduction in waist circumference compared with subjects in the control group [20, 24]. Thus, improvements in insulin sensitivity associated with the reduction in waist circumference may have protected the Glu9 allele carriers in the intervention group against the development of Type 2 diabetes.

Limitations of the study. Because the FSIGT was only performed in one of the five study centres, the number of subjects used in analyses of AIR, $\mathrm{S}_{\mathrm{I}}, \mathrm{S}_{\mathrm{G}}$ and DI is limited. However, baseline characteristics did not differ significantly between the Kuopio clinic subpopulation and the DPS study population as a whole [24]; therefore, our results could be generalised. To further analyse the interaction between $A D R A 2 B$ genotype and lifestyle factors, the entire study population was stratified according to study group or waist circumference. Although the group sizes were smaller, there was no apparent power problem in the testing of multiple hypotheses during subanalyses, given that they were both logical and relevant in a biological sense.

Several other gene polymorphisms have been tested using data from the DPS. Previously published positive associations between gene polymorphisms and the incidence of Type 2 diabetes in DPS include $I L-6$ ( $C$ $174 G)$ and TNF- $\alpha$ (G-308A) [37], PPAR-gamma2 (Pro12Ala) [38] and LIPC (G-250) [39]. Conversely, a number of gene polymorphisms have given negative results in DPS association studies, e.g. IGF-1R, IRS-1, $I R S-2$ [40]. It is probable that several positive associations between candidate genes and Type 2 diabetes are to be found in this study population, because subjects represent individuals at high risk of developing Type 2 diabetes. It is likely that many of these genes have a weak-to-moderate impact on diabetes incidence.

In conclusion, our results suggest that insulin secretion in response to an i.v. glucose stimulus is impaired in the presence of the Glu9 allele in subjects with impaired glucose tolerance. Interestingly, our results also suggest that the Glu9 allele increases the risk of Type 2 diabetes, particularly in individuals with central obesity who are not subjected to a lifestyle intervention.

Acknowledgements. This work has been financially supported by grants from the Academy of Finland (number 40758 to $\mathrm{M}$. Uusitupa; numbers 38387 and 46558 to J. Tuomilehto), the EVO-fund of Kuopio University Hospital (number 5106 to M. Uusitupa), the Ministry of Education of Finland, the Finnish Diabetes Foundation and the Sigrid Juselius foundation.

\section{References}

1. Kahn CR, Vicent D, Doria A (1996) Genetics of non-insulin-dependent (type-II) diabetes mellitus. Annu Rev Med 47:509-531

2. Gerich JE (1998) The genetic basis of type 2 diabetes mellitus: impaired insulin secretion versus impaired insulin sensitivity. Endocr Rev 19:491-503

3. Lillioja S, Mott DM, Spraul M et al. (1993) Insulin resistance and insulin secretory dysfunction as precursors of non-insulin-dependent diabetes mellitus. Prospective studies of Pima Indians. N Engl J Med 329:1988-1992

4. Kahn SE (2003) The relative contributions of insulin resistance and beta-cell dysfunction to the pathogenesis of Type 2 diabetes. Diabetologia 46:3-19

5. Elbein SC, Hasstedt SJ, Wegner K, Kahn SE (1999) Heritability of pancreatic beta-cell function among nondiabetic members of Caucasian familial type 2 diabetic kindreds. J Clin Endocrinol Metab 84:1398-1403

6. Lomasney JW, Lorenz W, Allen LF et al. (1990) Expansion of the alpha 2-adrenergic receptor family: cloning and characterization of a human alpha 2-adrenergic receptor subtype, the gene for which is located on chromosome 2. Proc Natl Acad Sci USA 87:5094-5098

7. Regan JW, Kobilka TS, Yang-Feng TL, Caron MG, Lefkowitz RJ, Kobilka BK (1988) Cloning and expression of a human kidney cDNA for an alpha 2-adrenergic receptor subtype. Proc Natl Acad Sci USA 85:6301-6305

8. Kobilka BK, Matsui H, Kobilka TS et al. (1987) Cloning, sequencing, and expression of the gene coding for the human platelet alpha 2-adrenergic receptor. Science 238:650-656

9. Ruffolo RR Jr, Nichols AJ, Stadel JM, Hieble JP (1993) Pharmacologic and therapeutic applications of alpha 2-adrenoceptor subtypes. Annu Rev Pharmacol Toxicol 33:243-279

10. Philipp M, Brede M, Hein L (2002) Physiological significance of alpha(2)-adrenergic receptor subtype diversity: one receptor is not enough. Am J Physiol Regul Integr Comp Physiol 283:R287-R295

11. Eason MG, Liggett SB (1993) Human alpha 2-adrenergic receptor subtype distribution: widespread and subtype-selective expression of alpha $2 \mathrm{C} 10$, alpha $2 \mathrm{C} 4$, and alpha 2C2 mRNA in multiple tissues. Mol Pharmacol 44:70-75

12. Lacey RJ, Chan SL, Cable HC et al. (1996) Expression of alpha 2- and beta-adrenoceptor subtypes in human islets of Langerhans. J Endocrinol 148:531-543

13. Heinonen P, Koulu M, Pesonen U et al. (1999) Identification of a three-amino acid deletion in the alpha2B-adrenergic receptor that is associated with reduced basal metabolic rate in obese subjects. J Clin Endocrinol Metab 84:2429-2433

14. Small KM, Brown KM, Forbes SL, Liggett SB (2001) Polymorphic deletion of three intracellular acidic residues of the alpha $2 \mathrm{~B}$-adrenergic receptor decreases $\mathrm{G}$ proteincoupled receptor kinase-mediated phosphorylation and desensitization. J Biol Chem 276:4917-4922

15. Sivenius K, Lindi V, Niskanen L, Laakso M, Uusitupa M (2001) Effect of a three-amino acid deletion in the alpha2B-adrenergic receptor gene on long-term body weight change in Finnish non-diabetic and type 2 diabetic subjects. Int J Obes Relat Metab Disord 25:1609-1614

16. Snapir A, Heinonen P, Tuomainen TP et al. (2001) An insertion/deletion polymorphism in the alpha2B-adrenergic receptor gene is a novel genetic risk factor for acute coronary events. J Am Coll Cardiol 37:1516-1522

17. Heinonen P, Jartti L, Jarvisalo MJ et al. (2002) Deletion polymorphism in the alpha2B-adrenergic receptor gene is associated with flow-mediated dilatation of the brachial artery. Clin Sci (Lond) 103:517-524 
18. Suzuki N, Matsunaga T, Nagasumi K et al. (2003) Alpha(2B)-adrenergic receptor deletion polymorphism associates with autonomic nervous system activity in young healthy Japanese. J Clin Endocrinol Metab 88:1184-1187

19. Dionne IJ, Turner AN, Tchernof A et al. (2001) Identification of an interactive effect of beta3- and alpha2b-adrenoceptor gene polymorphisms on fat mass in Caucasian women. Diabetes 50:91-95

20. Tuomilehto J, Lindstrom J, Eriksson JG et al. (2001) Prevention of type 2 diabetes mellitus by changes in lifestyle among subjects with impaired glucose tolerance. $\mathrm{N}$ Engl J Med 344:1343-1350

21. Eriksson J, Lindstrom J, Valle T et al. (1999) Prevention of Type II diabetes in subjects with impaired glucose tolerance: the Diabetes Prevention Study (DPS) in Finland. Study design and 1-year interim report on the feasibility of the lifestyle intervention programme. Diabetologia 42:793-801

22. Committee WHO (1985) Diabetes Mellitus Technical Report Series No. 742. WHO, Geneva

23. Bergman RN (1989) Lilly lecture 1989. Toward physiological understanding of glucose tolerance. Minimal-model approach. Diabetes 38:1512-1527

24. Uusitupa M, Lindi V, Louheranta A, Salopuro T, Lindström J, Tuomilehto J (2003) Long-term improvement in insulin sensitivity by changing lifestyles of people with impaired glucose tolerance: 4-year results from the Finnish Diabetes Prevention Study. Diabetes 52:2532-2538

25. Pacini G, Bergman RN (1986) MINMOD: a computer program to calculate insulin sensitivity and pancreatic responsivity from the frequently sampled intravenous glucose tolerance test. Comput Methods Programs Biomed 23:113-122

26. Bergman RN, Ader M, Huecking K, Van Citters G (2002) Accurate assessment of beta-cell function: the hyperbolic correction. Diabetes 51 [Suppl 1]:S212-S220

27. Aronne LJ (2002) Classification of obesity and assessment of obesity-related health risks. Obes Res 10 [Suppl 2]: 105S-115S

28. Bergman RN, Phillips LS, Cobelli C (1981) Physiologic evaluation of factors controlling glucose tolerance in man: measurement of insulin sensitivity and beta-cell glucose sensitivity from the response to intravenous glucose. J Clin Invest 68:1456-1467

29. LeRoith D (2002) Beta-cell dysfunction and insulin resistance in type 2 diabetes: role of metabolic and genetic abnormalities. Am J Med 113 [Suppl 6A]:3S-11S

30. Walston J, Silver K, Hilfiker H et al. (2000) Insulin response to glucose is lower in individuals homozygous for the Arg 64 variant of the beta-3-adrenergic receptor. J Clin Endocrinol Metab 85:4019-4022
31. Sesti G, Cardellini M, Marini MA et al. (2003) A common polymorphism in the promoter of $\mathrm{UCP} 2$ contributes to the variation in insulin secretion in glucose-tolerant subjects. Diabetes 52:1280-1283

32. Porzio O, Federici M, Hribal ML et al. (1999) The Gly972 $\rightarrow$ Arg amino acid polymorphism in IRS-1 impairs insulin secretion in pancreatic beta cells. J Clin Invest 104:357-364

33. Broadstone VL, Pfeifer MA, Bajaj V, Stagner JI, Samols E (1987) Alpha-adrenergic blockade improves glucose-potentiated insulin secretion in non-insulin-dependent diabetes mellitus. Diabetes 36:932-937

34. Devedjian JC, Pujol A, Cayla C et al. (2000) Transgenic mice overexpressing alpha2A-adrenoceptors in pancreatic beta-cells show altered regulation of glucose homeostasis. Diabetologia 43:899-906

35. Jewell-Motz EA, Liggett SB (1995) An acidic motif within the third intracellular loop of the alpha2 $\mathrm{C} 2$ adrenergic receptor is required for agonist-promoted phosphorylation and desensitization. Biochemistry 34:11946-11953

36. Rankinen T, Kim SY, Perusse L, Despres JP, Bouchard C (1999) The prediction of abdominal visceral fat level from body composition and anthropometry: ROC analysis. Int $\mathbf{J}$ Obes Relat Metab Disord 23:801-809

37. Kubaszek A, Pihlajamaki J, Komarovski V et al. (2003) Promoter polymorphisms of the TNF-alpha (G-308A) and IL-6 (C-174G) genes predict the conversion from impaired glucose tolerance to type 2 diabetes: the Finnish Diabetes Prevention Study Diabetes 52:1872-1876

38. Lindi VI, Uusitupa MI, Lindstrom J et al. (2002) Association of the Pro12Ala polymorphism in the PPAR-gamma2 gene with 3-year incidence of type 2 diabetes and body weight change in the Finnish Diabetes Prevention Study. Diabetes 51:2581-2586

39. Todorova B, Kubaszek A, Pihlajamaki J et al. (2004) The G-250A promoter polymorphism of the hepatic lipase gene predicts the conversion from impaired glucose tolerance to Type 2 diabetes mellitus: The Finnish Diabetes Prevention Study. J Clin Endocrinol Metab 89:2019-2023

40. Laukkanen O, Pihlajamaki J, Lindstrom J et al. (2004) Common polymorphisms in the genes regulating the early insulin signalling pathway: effects on weight change and the conversion from impaired glucose tolerance to Type 2 diabetes. The Finnish Diabetes Prevention Study. Diabetologia 47:871-877 